Brit. Heart J., 25, 1963, 748.

\title{
THE SOUNDS AND MURMURS IN TRANSPOSITION OF THE GREAT VESSELS
}

\author{
BY \\ BERTRAND WELLS \\ From The Hospital for Sick Children, Great Ormond Street, London W.C.1 \\ Received April 18, 1963
}

Complete transposition of the great vessels is a common cause of heart failure in infancy. The incidence of complete transposition in autopsies of children with congenital heart disease is nearly 20 per cent (Keith, Rowe, and Vlad, 1958), and the incidence in infants with heart failure and cyanosis is still higher. The infant usually presents with cyanosis, liver enlargement, and pulmonary œdema. The radiograph shows an enlarged 'egg-shaped' heart with narrow pedicle and increased vascularity of the lung fields. The electrocardiogram shows severe right ventricular hypertrophy. Hitherto the sounds and murmurs have not been considered to be of much help in the diagnosis. Keith et al. (1958) said that in the absence of pulmonary stenosis the second sound was of normal intensity or moderately accentuated and split and murmurs were inconstant and rarely significant. They stated that apical gallop rhythm was found in 80 per cent of the patients who died in heart failure. According to Miller, Baffes, and Wilkinson (1958) the tones are dynamic with the second sound increased, and when there is no ventricular septal defect or pulmonary stenosis there is usually no murmur. Nadas (1957) said that the heart sounds were not remarkable and that one-third of patients had no murmurs at all. These statements appear to be based on auscultatory rather than phonocardiographic evidence. The present study has been made to demonstrate by phonocardiography the sounds and murmurs that may be found in this condition.

\section{SubJeCTS AND METHODS}

Of the 65 patients with complete transposition of the great vessels who have been studied by phonocardiography many are progressing satisfactorily after surgical treatment. Although the diagnosis is well established in these cases it has been decided to limit the present study to 30 patients who have come to autopsy. The majority of these fall into three groups. Group I (13 cases) had no pulmonary stenosis and no septal defect other than an occasional small opening in the atrial septum: this group forms the main subject of the study. Group II (10 cases) had a ventricular septal defect but no pulmonary stenosis. Group III ( 3 cases) had a ventricular septal defect with pulmonary stenosis. In four cases there were other malformations, 2 having tricuspid atresia, 1 having mitral atresia, and 1 having a large atrial septal defect. The patients' age in 26 cases was under 8 months: the other 4 were aged 15 months, 5 years, 8 years, and 10 years. There were 17 male and 13 female subjects.

Phonocardiograms were taken with a Sanborn Stethocardiette using a logarithmic frequency response and a small open-bell chest piece. Tracings were taken at the apex, and the left sternal border in the second and fourth interspaces. Lead II of the electrocardiogram was used as reference tracing and the paper speed was $75 \mathrm{~mm}$./sec. No absolute measurements of intensity were made.

\section{RESULTS}

Group 1: Complete Transposition of the Great Vessels Without Septal Defect or Pulmonary Stenosis. The first heart sound was normal in all 13 cases studied (Cases 1 to 13), showing slight 
splitting in one case which was attributed to asynchronous mitral and tricuspid closure. There was no systolic click. The second sound showed variable splitting in seven cases. The relation of this splitting to respiration was not studied as respiratory tracings were not obtained. In two the second sound showed fixed splitting but this was narrow $(0.03 \mathrm{sec}$.). In four the second sound was single. The intensity of the second sound appeared to be increased by contrast with the first heart sound in three cases, and to be normal in ten.

The pattern of the systolic murmur was found to be the same in every case, showing a peak intensity before mid systole and becoming silent before the second heart sound. The peak intensity was compared to the mid point between the onset of the QRS complex of the cardiogram and the beginning of the second heart sound. The peak intensity occurred before this point in 10 cases and
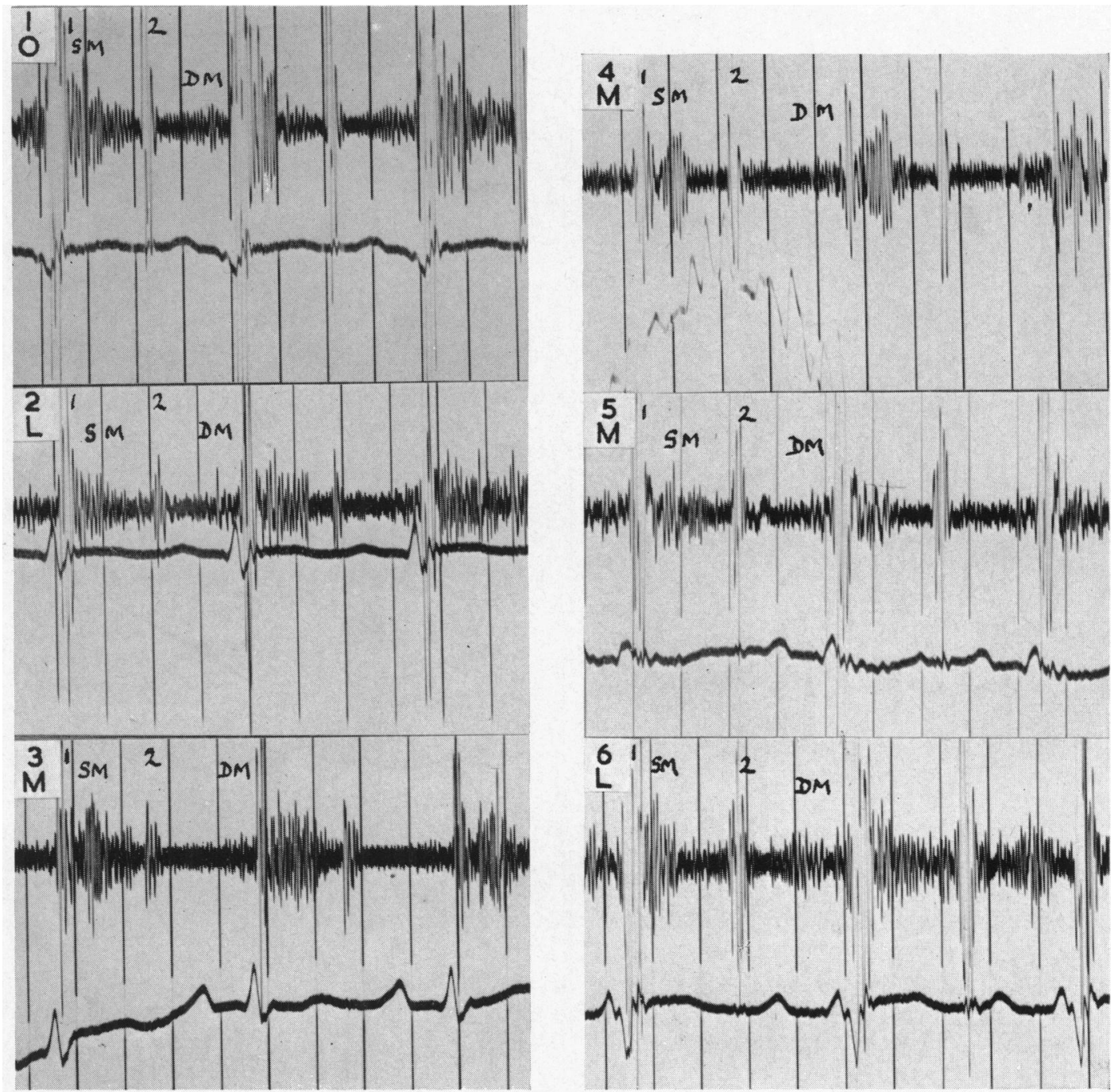

FIG. 1.-Cases 1 to 6 with complete transposition of the great vessels with intact septa and no pulmonary stenosis. In the top left-hand corner is the case number and below this is a letter indicating patency of the ductus arteriosus. L indicates a large patent ductus, $\mathbf{M}$ indicates a medium sized patent ductus; $\mathrm{O}$ indicates no patency. Upper tracing is logarithmic (high frequency) phonocardiogram. Lower tracing is electrocardiogram lead II. Time lines are $0 \cdot 1 \mathrm{sec}$. 

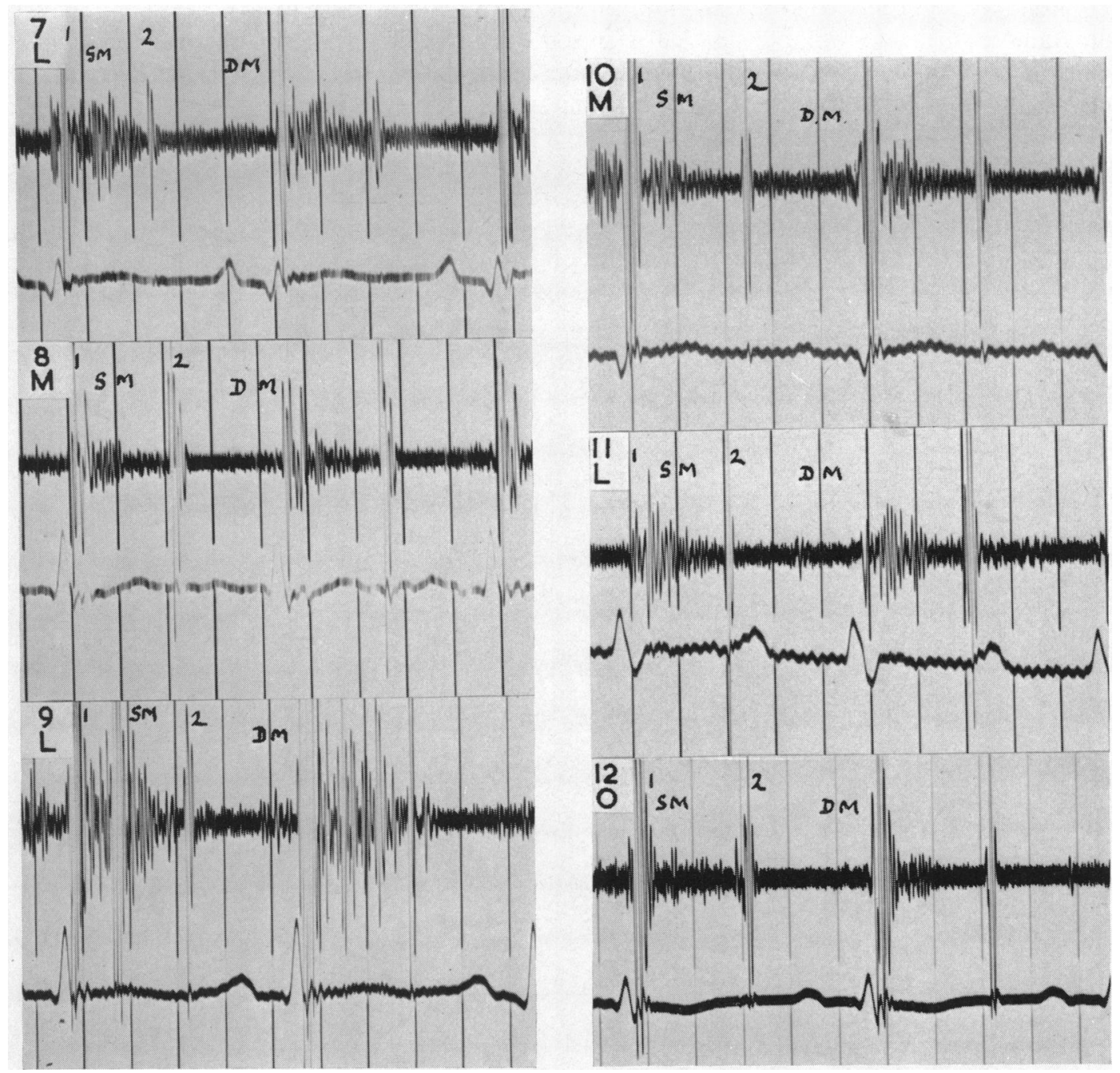

FIG. 2.-Cases 7 to 12 with complete transposition of the great vessels with intact septa and no pulmonary stenosis. Details as for Fig. 1.

at this point in the other three. The intensity of the murmur was equal to that of the second sound in one, half to equal in four, a quarter to half in seven, and less than a quarter in one. The vibrations were never of the coarse variety commonly found in innocent systolic murmurs (Wells, 1957). The frequency of the vibrations varied from 140 to 200 cycles a second with an average of 170 . The tracings of 12 of the 13 cases are shown in Fig. 1 and 2.

A diastolic murmur was present in all of the 13 cases. It was best recorded at the apex and less well seen at the left sternal border (Fig. 1 and 2). The murmur followed the apex of the $P$ wave of the cardiogram in every case. It disappeared before the onset of the first sound. In one patient with a prolonged $\mathrm{P}-\mathrm{R}$ interval there was a prolonged silent interval before the first heart sound.

The ductus arteriosus was found to be completely closed in 3 cases at autopsy: in the other 10 the ductus was patent. It was large in 6 and of moderate size in 4 . The systolic and diastolic 
murmurs tended to be of greater intensity when the ductus was large and of lesser intensity when the ductus was closed, but this relation was not constant. The illustrations (Fig. 1 and 2) show phonocardiograms from the fourth left interspace at the left sternal border where the systolic murmur was maximal, and the presence of a large ductus indicated by $\mathrm{L}$, a moderate ductus by $\mathrm{M}$, and no patency by $\mathrm{O}$.

Group II. Complete Transposition of the Great Vessels with Ventricular Septal Defect. This combination was present in 10 patients (Cases 14 to 23). Eight were under 4 months of age and did not differ in the pattern of the phonocardiograms from those without ventricular septal defect except for one patient, where (see Case 21, Fig. 4) the systolic murmur was louder and later than the others. There were 2 older children aged 8 and 10 years in whom the pattern was different: in both the first heart sound was of late onset. In the 8-year-old child both first and second sounds were occasionally split, and systolic and diastolic murmurs were of low intensity (Case 22, Fig. 4). In the 10 -year-old child there was a late ejection click $0.07 \mathrm{sec}$. after the first sound and a single second sound (Case 23, Fig. 4).
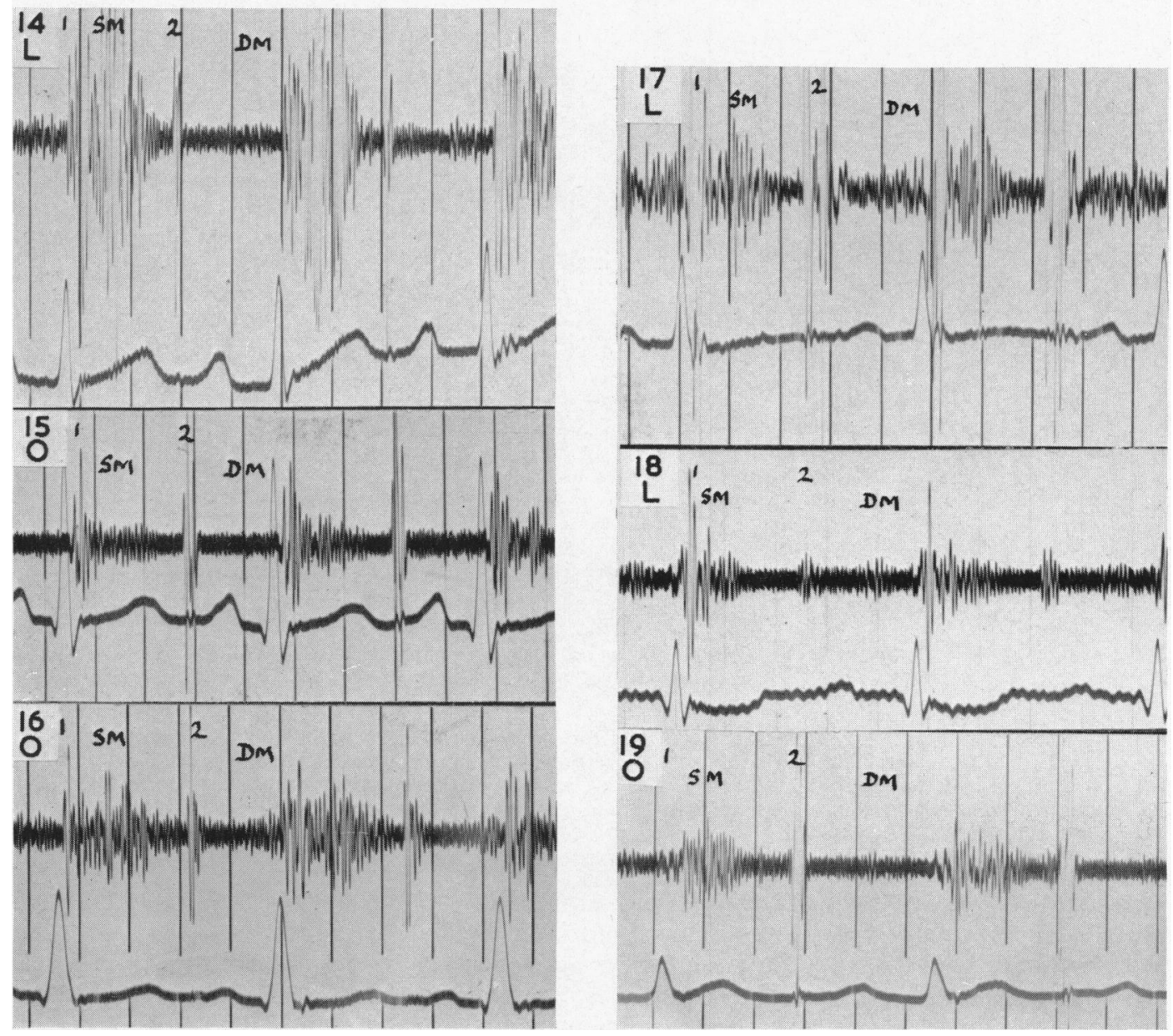

FIG. 3.-Cases 14 to 19 with complete transposition of the great vessels and ventricular septal defect without pulmonary stenosis. Details as for Fig. 1. The pattern is not considered to be different from that in Fig. 1 and 2. 

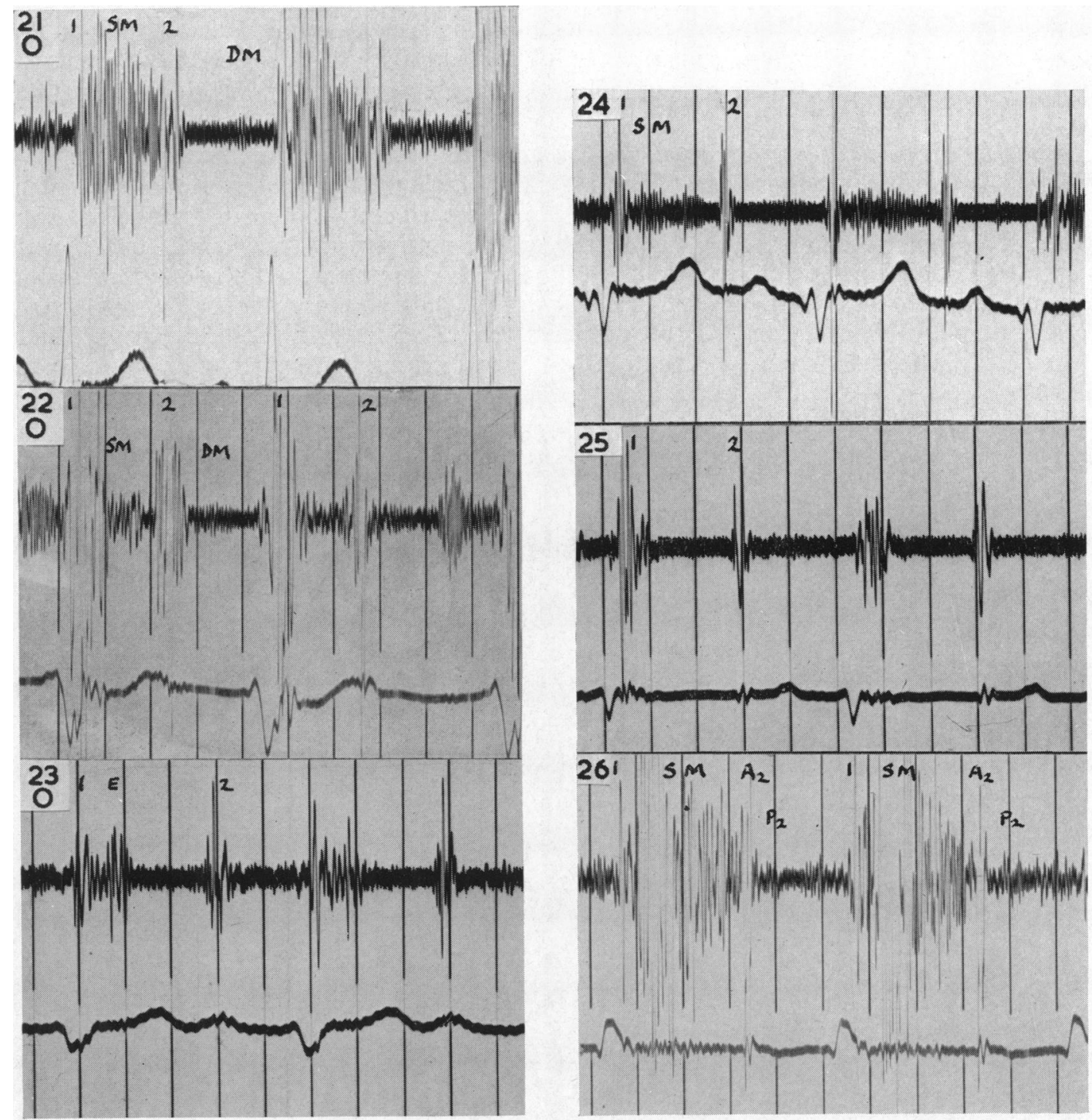

FIG. 4.-Cases 21 to 26 with complete transposition of the great vessels and ventricular septal defect. Details as for Fig. 1. Cases 21 to 23 had no pulmonary stenosis, but there is a longer systolic murmur in Case 21 , and a different pattern in Cases 22 and 23 (aged 8 and 10 years respectively) probably due to increased pulmonary vascular resistance. Cases 24 to 26 had pulmonary stenosis (subvalvar in Cases 24 and 25 and valvar in Case 26).

Group III. Complete Transposition of the Great Vessels with Ventricular Defect and Pulmonary Stenosis. Three patients had a ventricular septal defect and pulmonary stenosis. Two were similar anatomically in that they had an infundibular stenosis with a small ventricular septal defect (Cases 24 and 25, Fig. 4). In one of these there were no murmurs and a single second sound; in the other there was a long ejection murmur of low intensity and a single second sound. A third patient (Case 27) had dextrocardia with situs inversus abdominalis and valvular pulmonary stenosis. There was a systolic murmur of great intensity extending past the aortic valve closure sound, and the pulmonary valve closure sound was delayed and small. 
Transposition with Other Malformations. Four cases brought to autopsy did not fall into the above groups: 3 had mitral or tricuspid atresia and one had a large atrial septal defect. These cases were too few for analysis in the present study.

\section{DisCUSSION}

There were three features that when taken together in cyanotic infants are suggestive of transposition of the great vessels without pulmonary stenosis. These are (1) a second sound that shows variable or fixed narrow splitting, (2) a systolic murmur with peak intensity no later than mid systole, and (3) an apical diastolic murmur. When cyanosis is due to pulmonary stenosis rather than transposition there is usually a longer and later systolic murmur and a delayed and diminished pulmonary closure sound (Wells, 1958). When cyanosis is due to anomalous pulmonary venous drainage the systolic murmur may be similar but the second sound is widely split with accentuated P2. In significant aortic or pulmonary valve stenosis the systolic murmur always shows a peak intensity later in systole (Wells, 1958). Severe infundibular pulmonary stenosis may give a short early systolic murmur but such cases do not have narrow splitting of the second sound or a diastolic murmur. The diastolic murmur in cases of transposition is probably due to increased mitral flow. The diastolic murmur ceases before the first heart sound which differentiates it from the murmur of mitral stenosis. The presence or absence of patency of the ductus arteriosus is not indicated by the sound tracings, but intense systolic and diastolic murmurs are more common when a large patent ductus is present.

The presence of a ventricular septal defect does not significantly affect the auscultatory features except in older patients who show changes attributable to increased pulmonary vascular resistance. In these the phonocardiogram is indistinguishable from that of ventricular septal defect with reversed shunt (Eisenmenger situation) without transposition.

The inconspicuous systolic murmur in the two patients with infundibular stenosis could be explained by the fact that the stenosis was severe and lay behind the large aorta. The patient with the loud systolic murmur and split second sound had the same phonocardiographic pattern as in isolated pulmonary valve stenosis. Although this patient had dextrocardia and situs inversus abdominalis the pulmonary artery was posterior to the aorta and it is not clear why the pattern differed so much from that of the two previous patients.

\section{SUMMARY}

Phonocardiograms of 30 patients with transposition of the great vessels were chosen for study because their hearts were subsequently examined at autopsy.

Thirteen had no pulmonary stenosis or septal defect other than a small patency of the foramen ovale. All showed an early ejection systolic murmur maximal at or before the mid-point between the onset of the QRS and the second sound. All but four showed some splitting of the second sound without diminution of the pulmonary component. All showed an apical flow murmur in diastole. These features taken together are strong evidence of transposition of the great vessels. A patent ductus is usually present but its size and presence cannot be deduced with assurance from the phonocardiogram.

Ten patients had transposition of the great vessels with ventricular septal defect. Eight of these were under 4 months of age and the phonocardiograms did not differ significantly from the above. The others were aged 8 and 10 years and showed changes attributed to increasing pulmonary vascular resistance.

Three patients had transposition of the great vessels with ventricular septal defect and pulmonary stenosis. In two the systolic murmur was of low intensity, probably because of extreme infundibular stenosis located behind the aorta. The other had dextrocardia with valvular stenosis with a loud systolic murmur and late small pulmonary closure sound.

I am grateful to Dr. R. E. Bonham Carter and Mr. D. J. Waterston for permission to study their patients and for their help. 


\section{REFERENCES}

Keith, J. D., Rowe, R. D., and Vlad, P. (1958). Heart Disease in Infancy and Childhood. Macmillan, New York. Miller, R. A., Baffes, T. C., and Wilkinson, A. A. (1958). Transposition of the great vessels. Pediat. Clin. N. Amer., 5,1109 .

Nadas, A. (1957). Pediatric Cardiology. Saunders, Philadelphia.

Wells, B. (1957). The graphic configuration of innocent systolic murmurs. Brit. Heart J., 19, 129.

Wells, B. G. (1958). The effect of valvotomy on the murmurs of pulmonary and aortic stenosis. Brit. Heart J., 20, 523. 